Original Research Paper

\title{
Serological and Molecular Investigation of Middle East Respiratory Syndrome Coronavirus and Equine Herpesviruses in Horses at Southwestern Saudi Arabia
}

\author{
Ali S. Alqahtani \\ Department of Medical Laboratory Sciences, Faculty of Applied, Medical Sciences, Najran University, Najran, Saudi Arabia
}

Article history

Received: 23-08-2020

Revised: 28-09-2020

Accepted: 29-09-2020

Email: almezherali@gmail.com

\begin{abstract}
Host reservoirs other than dromedaries for the Middle East Respiratory Syndrome Coronavirus (MERS-CoV) still to be unknown. Equine Herpesviruses (EHVs) are widespread in equine populations worldwide. In this study, the presence of MERS-CoV, Equine Herpesviruses type 1 (EHV-1) and 4 (EHV-4) in horses in Najran, southwestern of Saudi Arabia was investigated. One hundred and thirty four blood samples collected from horses of different ages and sex. The samples tested for the presence of specific antibodies by ELISA and viral RNA and DNA by PCR. The ELISA results were positive for equine herpesviruses 1 and 4 with percent of 23.1 and $70.8 \%$ respectively; while all tested samples were negative for MERS-CoV. The PCR results showed that all samples were negative for all three viruses. As the history of the horses showed no previous vaccination or infection with equine herpesviruses, these results might refer to equine herpes subclinical infection. The results indicate also that horses were free from MESR-CoV infection.
\end{abstract}

Keywords: Equine, Herpesvirus, MERS, ELISA, PCR, Saudi Arabia

\section{Introduction}

Middle East Respiratory Syndrome Coronavirus (MERS-CoV) first appeared in 2012 in Saudi Arabia and is now a worldwide concern (Zaki et al., 2012). The World Health Organization (2019) had confirmed up to 2428 cases from 27 countries. The dyed cases were 791, most of them reported in Saudi Arabia. Infection through contact with dromedary camels is the major route in primary infection of human. However, human-to-human contact is the main rout of human infection (Sabir et al., 2016; Reusken et al., 2016). Previous serologic surveys of equines and ruminants did not indicate circulation of MERS-CoV among these animals (Adney et al., 2016; Hemida et al., 2013; Meyer et al., 2015). The ability of the virus to jump species barriers and infect other animals is possible. The virus was capable of infecting cell cultures from mammals of many species (Chan et al., 2013). Horses might be the highly susceptible host to MERS-CoV because of their great similarity in DPP-4 amino acids at positions critical for binding of MERS-CoV spike protein (Bosch et al., 2013; van Doremalen et al., 2014; Vergara-Alert et al., 2017). Moreover, primary horse cells have shown production of infectious virus progeny and viral RNA, which is needed for virus transmission (Bosch et al., 2013; van Doremalen et al., 2014; Vergara-Alert et al., 2017).

Equine Herpesvirustype 1 and 4 (AHV-1 and EHV-4) belong to the subfamily Alpha-herpesvirinae, genus Varicellovirus of the Herpesviridae family. Five strains can infect horses. However, EHV-1 and EHV-4 have the most impact on equine industry (Davison et al., 2009). Both viruses are highly contagious and spread from horse to horse by inhalation of respiratory secretions, as well as direct contact. Latency and periodical reactivation of EHV are responsible for its spread in horses and are key features in the epidemiology of the virus (Roizman, 1996; Slater, 2007; Reed and Toribio, 2004). EHV-1 has a wider host range than that of EHV-4 and can result in neonatal death, abortions, respiratory disease and Equine Herpes virus Myeloencephalopathy (EHM) (Ma et al., 2013). EHV-1 and EHV-4 are different also in virus entry and in their interference with the innate immune response (Patel and Heldens, 2005; Allen et al., 2004). EHV-1 shows a strong tropism for epithelial cells of the upper respiratory tract and affected 
horses may have respiratory signs and fever but subclinical infections are common. The virus spreads systematically through infected mononuclear cells to central nervous system or the pregnant uterus leading to neurological disease or abortion (Patel and Heldens, 2005; Allen et al., 2004).

Although equine herpesviruses have worldwide distribution, they did not receive much concern in literature in Saudi Arabia (SA). The only available Virological survey of EHVs among horses conducted approximately 15 years ago (Frölich et al., 2005). This study conducted in Najran area, southwest of SA for two main objectives. The first one was to determine the prevalence of infection with equine herpesviruses 1 and 4; and the second was to investigate MERS-CoV infection situation in horses.

\section{Materials and Methods}

\section{Study Area and Samples}

The study included seven stables in different parts of Najran area. Blood samples collected from 134 horses in risk areas (in close contact with camels). The horses were of different ages and sex and all horses were apparently healthy. After collection, blood samples subdivided into two parts, first part on EDTA for viral RNA detection and the other part without EDTA for MERS-CoV specific antibodies detection. The samples transported to the laboratory in cool boxes. After blood clotting, it was centrifuged at 5,000 rpm for $5 \mathrm{~min}$ and sera were separated and stored in labeled cryovials at $20^{\circ} \mathrm{C}$ till used. Ethical rules and animal welfare were taken into account during sampling. The study approved by the Institutional Ethics Committee at Najran University (ethical number: 15-01-18 EC).

\section{Serological Identification by ELISA}

For MERS-CoV identification, the test was done according to the protocol of Meyer et al. (2015). The specific $\mathrm{S} 1$ antibodies in the serum samples were tested as described by the producer, with slight modification, in which anti-human conjugate were replaced by anti-equine conjugate. For equine herpesviruses identification, the test was done according to the protocol of Lang et al. (2013). ELISA kits were purchased from Euroimmune Co, Germany. The optical density was measured by spectrophotometer at $450 \mathrm{~nm}$ (TriStar LB941, Berthold).
Positive and negative controls were used in each ELISA performed throughout the study.

\section{Molecular Identification by PCR}

For MERS-CoV identification, viral RNA was extracted from blood cells by using DNA-RNA extraction kits (Stratec Molecular, Germany). The RNA extracts were detected by real time quantitative reverse transcriptase PCR (RT-qPCR) by using OneStep RTPCR reagents according to the manufacturer's instructions (Bioline, Germany). The following primers were used, forward primer: GCAACGCGCGATTCAGTT, the reverse primer: CCTCTACACGGGACCCATA and the probe: 6FAMCTCTTCACATAATCGCCCCGAGCTCG-BHQ-1.

For herpes virus detection, viral DNA was extracted from the whole blood using the Mini Kit (Stratek Molecular, Germany) from samples according to the manufacturer's instructions. The viral extracts were detected by Real Time Polymerase Chain Reaction (RTPCR). The protocol was applied according to Damiani et al. (2014). Specific primers for EHV-1: (Fw: 50ATACGTCCCTGTCCGACAGAT-30 and Rv: 50GGTACT CGGCCTTTGACGAA -30) and a probe (506Fam-TGAGACC-GAAGATCTCCTCCACCGA-

BHQ1-30) targeting EHV-1 gB were used. The same protocol was used for identification of EHV-4 except for using of the following primers and probe: FW 5'-CGC AGA GGA TGG AGA CTT TTA CA -3' RV 5'-CAT GAC CGT GGG GGT TCA A -3' Probe EHV4 5'FAMCTG CCC GCC GCC TAC TGG ATC-TAMRA. PCR was carried out in 30 cycles of $94^{\circ} \mathrm{C}$ for $30 \mathrm{sec}, 54^{\circ} \mathrm{C}$ for $30 \mathrm{sec}, 72^{\circ} \mathrm{C}$ for $1 \mathrm{~min}$ followed by a $10 \mathrm{~min}$ extension at $72^{\circ} \mathrm{C}$. PCR was performed with the Applied Biosystems 7500 FAST real-time PCR system.

\section{Results}

Anti-MERS-CoV IgG ELISA results showed that all 134 samples were negative for MERS-CoV antibodies. While out of the 134 tested samples for herpesviruses, 31 samples were positive for EHV-1 and 95 samples were positive for EHV-4 (Table 1). The antibodies were detected in all ages and in both males and females. The RT-PCR result was negative for MERS$\mathrm{CoV}$ in the all tested samples. Furthermore, the RTPCR result showed that all samples of both EHV-1 and EHV-4 were negative.

Table 1: Results of MERS and equine herpes viruses by ELISA and RT-PCR

\begin{tabular}{llll} 
Virus & Total number of samples & Number of ELISA positive $(\%)$ & Number of RT-PCR positive $(\%)$ \\
\hline MERS & 134 & $0(0 \%)$ & $0(0 \%)$ \\
EHV -1 & 134 & $31(23.1 \%)$ & $0(0 \%)$ \\
EHV -4 & 134 & $95(70.8 \%)$ & $0(0 \%)$ \\
\hline
\end{tabular}




\section{Discussion}

World Health Organization (2019) identified MERS$\mathrm{CoV}$ as a potential cause of future epidemics and listed the virus for urgent research. EHV-1 and EHV-4 affect horse populations on all continents. Accurate diagnosis remains a problem facing horse owners and veterinarians (Davison et al., 2009; Roizman, 1996; Slater, 2007). In this study, we examined for the first time the prevalence of these viruses in horses in Najran area. MERS-CoVendemic areas, such as Saudi Arabia, should be scanned regularly for virus epidemiology. Horses were the target of many studies to examine the possibility of contracting MERS-CoV for several reasons. First, the great similarity between the virus receptors found on both human and horse cells. Second, horses were recently diagnosed with corona virus infection and equine $\mathrm{CoV}$ belongs to the same subfamily, Beta-coronavirus, of MERS-CoV. Najran area showed many infections of human and camels with MERS-CoV (Al-Ayed et al., 2014; Alghamdi et al., 2014). Because there is a wide cross contact between camel, horses and human, it was important to identify whether the horses in the region may contract the disease. Our results showed that all samples were negative for MERS antibodies and RNA. Our results are in agreement with other studies that have been done in and out Saudi Arabia (Adney et al., 2016; Hemida et al., 2013; Meyer et al., 2015; Kasem et al., 2018). However, very recent studies showed the ability of the virus to infect ruminant and donkeys (Kandeil et al., 2019; Ali et al., 2017). Further works are needed to follow up this condition.

ELISA results of equine herpesviruses 1 and 4 were determined as high as 22.9 and $70.8 \%$ respectively. These results are in accordance with previous studies conducted elsewhere in the world (Kasem et al., 2018; Kandeil et al., 2019; Ali et al., 2017). The viral DNA could not detected in all ELISA positive samples. The history indicates that these horses were not previously vaccinated or infected, which refer to possible previous subclinical infection with subsequent state of latency. Latent EHV-1 and EHV-4 are widespread in the equines and the site of latency is mainly the lymph nodes of the respiratory tract (Edington et al., 1994; Pusterla et al., 2010; Welch et al., 1992). The seriousness of these results lies in two points. The possibility of reactivation of the latent virus with subsequent overt infection, which could cause heavy economic losses. The second point is the possibility of EHV-1 to become a zoonotic disease and infect human being. The potential of EHV-1 to cross species barriers was demonstrated (Wozniakowski and Samorek-Salamonowicz, 2015; Washburne et al., 2018; Trapp et al., 2005). Productive intranasal infection with EHV-1 of other species as hamster and mouse were shown. Herpesviruses that can infect human cell culture theoretically represent zoonotic threats. EHV-
1 was able to infect human epithelial cells and peripheral blood mononuclear cells (McStreet et al., 1992; Laurent et al., 2001). Although there was no clinical infection and the presence of the nucleic acid was not detected, the very high proportion of equine herpesviruses antibodies, especially type 4 , should not be neglected. Horses having latent virus, even at low levels, are considered as potentially risk.

In conclusion, we have determined for the first time in Najran region and even in the whole Saudi Arabia the prevalence of equine herpesviruses antibodies in horses. Following up these horses are important and regular vaccinations should be considered for the future prevention of the disease. Horses did not show any infection with MERS-CoV.

\section{Ethical Approval}

The study was approved by the Institutional Ethics Committee at Najran University.

\section{References}

Al-Ayed, M. S., Asaad, A. M., Qureshi, M. A., \& Ameen, M. S. (2014). Viral etiology of respiratory infections in children in southwestern Saudi Arabia using multiplex reverse-transcriptase polymerase chain reaction. Saudi medical journal, 35(11), 1348.

Adney, D. R., Brown, V. R., Porter, S. M., BielefeldtOhmann, H., Hartwig, A. E., \& Bowen, R. A. (2016). Inoculation of goats, sheep and horses with MERS-CoV does not result in productive viral shedding. Viruses, 8(8), 230.

Alghamdi, I. G., Hussain, I. I., Almalki, S. S., Alghamdi, M. S., Alghamdi, M. M., \& El-Sheemy, M. A. (2014). The pattern of Middle East respiratory syndrome coronavirus in Saudi Arabia: a descriptive epidemiological analysis of data from the Saudi Ministry of Health. International journal of general medicine, 7, 417.

Ali, M., El-Shesheny, R., Kandeil, A., Shehata, M., Elsokary, B., Gomaa, M., ... \& Fasina, F. O. (2017). Cross-sectional surveillance of Middle East respiratory syndrome coronavirus (MERS-CoV) in dromedary camels and other mammals in Egypt, August 2015 to January 2016. Euro Surveill, 22(11), 30487.

Allen, G. P., Kydd, J. H., Slater, J. D., \& Smith, K. C. (2004). Equid herpesvirus-1 and equid herpesvirus-4 infections, p 829-859. Coetzer JAW, Tustin RC, Infectious diseases of livestock. Oxford University Press, Oxford, United Kingdom.

Bosch, B. J., Raj, V. S., \& Haagmans, B. L. (2013). Spiking the MERS-coronavirus receptor. Cell research, 23(9), 1069-1070. 
Chan, J. F. W., Chan, K. H., Choi, G. K. Y., To, K. K. W., Tse, H., Cai, J. P., ... \& Lau, S. K. P. (2013). Differential cell line susceptibility to the emerging novel human betacoronavirus 2c EMC/2012: implications for disease pathogenesis and clinical manifestation. The Journal of infectious diseases, 207(11), 1743-1752.

Damiani, A. M., de Vries, M., Reimers, G., Winkler, S., \& Osterrieder, N. (2014). A severe equine herpesvirus type 1 (EHV-1) abortion outbreak caused by a neuropathogenic strain at a breeding farm in northern Germany. Veterinary Microbiology, 172(3-4), 555-562.

Davison, A. J., Eberle, R., Ehlers, B., Hayward, G. S., McGeoch, D. J., Minson, A. C., ... \& Thiry, E. (2009). The order herpesvirales. Archives of virology, 154(1), 171-177.

Edington, N., Welch, H. M., \& Griffiths, L. (1994). The prevalence of latent equid herpesviruses in the tissues of 40 abattoir horses. Equine veterinary journal, 26(2), 140-142.

Frölich, K., Hamblin, C., Jung, S., Ostrowski, S., Mwanzia, J., Streich, W. J., ... \& Anajariyah, S. (2005). Serologic surveillance for selected viral agents in captive and free-ranging populations of Arabian oryx (Oryx leucoryx) from Saudi Arabia and the United Arab Emirates. Journal of wildlife diseases, 41(1), 67-79.

Hemida, M. G., Perera, R. A., Wang, P., Alhammadi, M. A., Siu, L. Y., Li, M., ... \& Peiris, M. (2013). Middle East Respiratory Syndrome (MERS) coronavirus seroprevalence in domestic livestock in Saudi Arabia, 2010 to 2013. Eurosurveillance, 18(50), 20659.

Kandeil, A., Gomaa, M., Shehata, M., El-Taweel, A. Kayed, A. E., Abiadh, A., ... \& Mahmoud, S. (2019). Middle East respiratory syndrome coronavirus infection in non-camelid domestic mammals. Emerging microbes \& infections, 8(1), 103-108.

Kasem, S., Qasim, I., Al-Hufofi, A., Hashim, O., Alkarar, A., Abu-Obeida, A., ... \& Babekr, N. (2018). Crosssectional study of MERS-CoV-specific RNA and antibodies in animals that have had contact with MERS patients in Saudi Arabia. Journal of infection and public health, 11(3), 331-338.

Lang, A., de Vries, M., Feineis, S., Müller, E., Osterrieder, N., \& Damiani, A. M. (2013). Development of a peptide ELISA for discrimination between serological responses to equine herpesvirus type 1 and 4. Journal of virological methods, 193(2), 667-673.

Laurent, S., Esnault, E., Dambrine, G., Goudeau, A., Choudat, D., \& Rasschaert, D. (2001). Detection of avian oncogenic Marek's disease herpesvirus DNA in human sera. Journal of General Virology, 82(1), 233-240.
Ma, G., Azab, W., \& Osterrieder, N. (2013). Equine herpesviruses type 1 (EHV-1) and 4 (EHV-4)masters of co-evolution and a constant threat to equids and beyond. Veterinary microbiology, 167(1-2), 123-134

McStreet, G. H., Elkunk, R. B., \& Latiwonk, Q. I. (1992). Investigations of environmental conditions during cluster indicate probable vectors of unknown exogenous agent (s) of multiple sclerosis. Comparative immunology, microbiology and infectious diseases, 15(1), 75-77.

Meyer, B., García-Bocanegra, I., Wernery, U., Wernery, R., Sieberg, A., Müller, M. A., ... \& Eckerle, I. (2015). Serologic assessment of possibility for MERS-CoV infection in equids. Emerging infectious diseases, 21(1), 181.

Patel, J. R., \& Heldens, J. (2005). Equine herpesviruses 1 (EHV-1) and 4 (EHV-4)-epidemiology, disease and immunoprophylaxis: a brief review. The Veterinary Journal, 170(1), 14-23.

Pusterla, N., Mapes, S., \& Wilson, W. D. (2010). Prevalence of equine herpesvirus type 1 in trigeminal ganglia and submandibular lymph nodes of equids examined postmortem. Veterinary Record, 167(10), 376-379.

Reed, S. M., \& Toribio, R. E. (2004). Equine herpesvirus 1 and 4. Veterinary Clinics: Equine Practice, 20(3), 631-642.

Reusken, C. B., Schilp, C., Raj, V. S., De Bruin, E., Kohl, R. H., Farag, E. A., ... \& Koopmans, M. P. (2016). MERS-CoV infection of alpaca in a region where MERS-CoV is endemic. Emerging Infectious Diseases, 22(6), 1129.

Roizman, B. (1996). Herpesviridae. In: Field, B. N., Knipe, D. M., Howley, P. M., Channock, R. M., Melnick, J. L., Monath, T. P., Roizman, B., \& Straus, S. E., editors. Virology. (pp. 2221-2230.), Lippincott-Raven; Philadelphia, NY, USA.

Sabir, J. S., Lam, T. T. Y., Ahmed, M. M., Li, L., Shen, Y., Abo-Aba, S. E., ... \& Alharbi, N. S. (2016). Cocirculation of three camel coronavirus species and recombination of MERS-CoVs in Saudi Arabia. Science, 351(6268), 81-84.

Slater, J. (2007). Equine herpesviruses. In: Sellon, D. C., \& Long, M. T., editors. Equine infectious diseases, (pp. 134-153.). Saunders Elsevier, USA.

Trapp, S., von Einem, J., Hofmann, H., Köstler, J., Wild, J., Wagner, R., ... \& Osterrieder, N. (2005). Potential of equine herpesvirus 1 as a vector for immunization. Journal of virology, 79(9), 5445-5454.

van Doremalen, N., Miazgowicz, K. L., Milne-Price, S., Bushmaker, T., Robertson, S., Scott, D., ... \& Munster, V. J. (2014). Host species restriction of Middle East respiratory syndrome coronavirus through its receptor, dipeptidyl peptidase 4 . Journal of virology, 88(16), 9220-9232. 
Vergara-Alert, J., van den Brand, J. M., Widagdo, W., \& Muñoz, M. (2017). Livestock susceptibility to infection with Middle East respiratory syndrome coronavirus. Emerging infectious diseases, 23(2), 232.

Washburne, A. D., Crowley, D. E., Becker, D. J., Olival, K. J., Taylor, M., Munster, V. J., \& Plowright, R. K. (2018). Taxonomic patterns in the zoonotic potential of mammalian viruses. PeerJ, 6, e5979.

Welch, H. M., Bridges, C. G., Lyon, A. M., Griffiths, L., \& Edington, N. (1992). Latent equid herpesviruses 1 and 4: detection and distinction using the polymerase chain reaction and co-cultivation from lymphoid tissues. Journal of General Virology, 73(2), 261-268.
World Health Organization. (2019). Middle East respiratory syndrome coronavirus (MERS-CoV).

Wozniakowski, G., \& Samorek-Salamonowicz, E. (2015). Animal herpesviruses and their zoonotic potential for cross-species infection. Annals of Agricultural and Environmental Medicine, 22(2).

Zaki, A. M., Van Boheemen, S., Bestebroer, T. M., Osterhaus, A. D., \& Fouchier, R. A. (2012). Isolation of a novel coronavirus from a man with pneumonia in Saudi Arabia. New England Journal of Medicine, 367(19), 1814-1820. 